\title{
Applying New Zealand's risk tools internationally: Case studies from Samoa and Vanuatu
}

\author{
Finn Scheele ${ }^{1, *}$, Titimanu Simi ${ }^{2}$, Johnie Tarry Nimau ${ }^{3}$, Shaun Williams ${ }^{4}$, Ryan Paulik ${ }^{4}$, \\ ShengLin Lin ${ }^{1}$, Juliana Ungaro ${ }^{4}$, Paula Holland ${ }^{4}$, and Richard Woods ${ }^{1}$ \\ ${ }^{1}$ GNS Science, New Zealand \\ ${ }^{2}$ National Disaster Management Office, Ministry of Natural Resources and Environment, Samoa. \\ ${ }^{3}$ National Disaster Management Office, Ministry of Climate Change, Vanuatu. \\ ${ }^{4}$ National Institute of Water and Atmospheric Research (NIWA), New Zealand.
}

\begin{abstract}
Decision makers require disaster risk management (DRM) tools to better prepare for and respond to emergencies, and for making sound landuse planning decisions. Risk tools need to incorporate multiple hazard and asset types, and have the versatility to adapt to local contexts. RiskScape is a natural hazards impact and loss modelling tool developed to support DRM related decision making in New Zealand. The RiskScape software has benefitted from over 10 years of research and development, and has been used for a diverse range of applications both in New Zealand and internationally. Experience and challenges in applying RiskScape beyond New Zealand are highlighted in this study through the tailoring of RiskScape for Pacific Island countries, as part of the Pacific Risk Tool for Resilience (PARTneR) project. PARTneR is a collaborative project between the National Institute of Water and Atmospheric Research (NIWA), GNS Science, the disaster management offices of Samoa and Vanuatu, and the Geoscience Division of the Pacific Community. RiskScape is applied through three demonstration case studies for each country, focused on prominent natural hazards.
\end{abstract}

\section{Introduction}

Disasters in the Pacific undermine development, but the impact of future hazard events can be greatly reduced by using science-based risk assessments. These may be used to inform land use planning, ensure socio-economic development is protected, and guide investment decisions for building resilience. Disaster Risk Reduction (DRR), Management (DRM) and land use planning should be underpinned by sound, context-derived risk information. However, in the Pacific this is limited because of low institutional capacity, as well as a lack of appropriate tools and processes for gathering, analysing and applying existing and future disaster risk information to underpin and prioritise investment in resilient development.

\footnotetext{
* Corresponding author; f.scheele@gns.cri.nz
} 
To address these issues the PARTneR Project aims to enable Pacific government ministries and stakeholder organisations to effectively develop and use risk-based information to support development decision-making and planning. The implementation of the project is based on three core components;

1. The co-design and development of a natural hazards impact mapping and modelling tool for the Pacific

2. Integrated disaster risk data management systems

3. Sustainable targeted and tailored training and skills development

PARTneR is 3-year project which began in July 2016 and is being piloted in Samoa [1] and Vanuatu [2]. It is being funded through the New Zealand Partnerships Fund administered by the Ministry of Foreign Affairs and Trade, and is managed by NIWA in collaboration with 5 partners: the Samoa Disaster Management Office; the Vanuatu Disaster Management Office working with the Vanuatu Meteorology and Geo-Hazards Department; GNS Science and the Pacific Community - Geoscience, Energy and Maritime Division (SPC).

RiskScape is an open access disaster impact mapping and loss modelling software application built on a generic risk model framework for natural hazards (Figure 1). The software system is used for storing, processing, analysing and visualising natural hazard information such as damages to assets, economic losses, human casualties, and reinstatement costs. It was developed in New Zealand by NIWA and GNS Science and is spatially configured for use worldwide and designed for multiple hazard, asset, vulnerability and loss types [3].

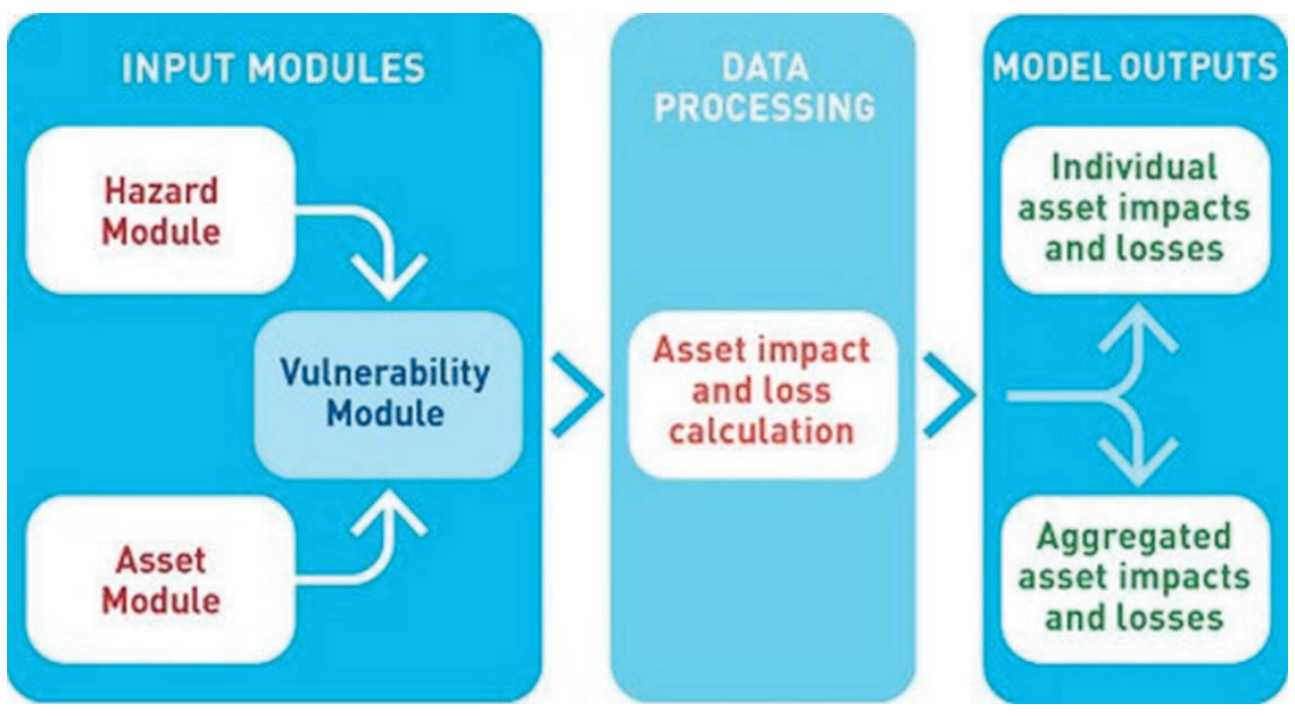

Figure 1. The RiskScape software model framework.

Within RiskScape spatial information is held in hazard and asset modules which support exposure modelling, a method commonly employed in risk identification. In these models, RiskScape identifies assets located within a modelled natural hazard scenario extent and reports whether assets are exposed or not exposed to the hazard. Vulnerability models used in combination with this information enables risk modelling to be performed. Asset impact and loss outputs can be compared to determine the most cost-effective form of risk treatment. 
The PARTneR project aims to tailor the RiskScape tool to meet the local context of Pacific Island countries for application in DRM, and is being piloted within the Samoan and Vanuatuan contexts. The tailoring of RiskScape and the application of outputs for decision making is framed around three demonstration case studies for each country that were identified by local stakeholders during initial inception workshops.

\section{Samoa case studies}

The three demonstration case studies for Samoa are:

1. Tsunami risk and loss modelling for response planning;

2. Near real time impact forecasting for Tropical Cyclone related floods;

3. Landslide risk for land use planning.

\subsection{Case Study 1: Tsunami risk and loss modelling for response planning}

Samoa's close proximity to the Northern Tongan Subduction Arc (NTSA) means that the southern shores of Samoa are directly exposed to a major tsunami originating at this source. The recent 2009 South Pacific Tsunami which originated at the NTSA caused major destruction to properties and businesses, displaced families and communities, and culminated in more than 140 deaths along southeast Upolu [4]. Samoa Case Study 1 applies the RiskScape loss model framework to inform emergency response activities for future tsunami events. This case study is framed around exposure and/or impact models for three key scenarios:

- Exposure model for:

○ Apia assets located within current tsunami evacuation zones.

- Impact models for:

- A southeast Upolu village affected by the 2009 South Pacific Tsunami (e.g., Lalomanu or Saleapaga); and/or

- Apia if exposed to a worst-case tsunami associated with a probable magnitude 9+ earthquake at the Northern Tongan Subduction Arc (NTSA).

Tsunami exposure and impact models require specific functions to generate information for emergency response activities. Exposure models simply report information about assets of interest located within an area identified as at risk to tsunami hazards, as shown in the example in Figure 2. Impact models apply vulnerability functions that estimate the expected direct and/or indirect damage sustained by different asset types in response to tsunami hazards of increasing intensity (e.g. flow depth).

Model outputs are intended to inform emergency readiness and response activities for future tsunami events in Samoa. The model's vulnerability component must be underpinned by an understanding of asset susceptibility to direct and indirect damage when exposed to tsunami hazards of varying intensity. The approach used in this case study is to derive this knowledge through a literature review of existing tsunami damage reports and journal papers 
relevant to Samoa, and input from local experts on the characteristics of assets which influence their susceptibility to tsunami damage.

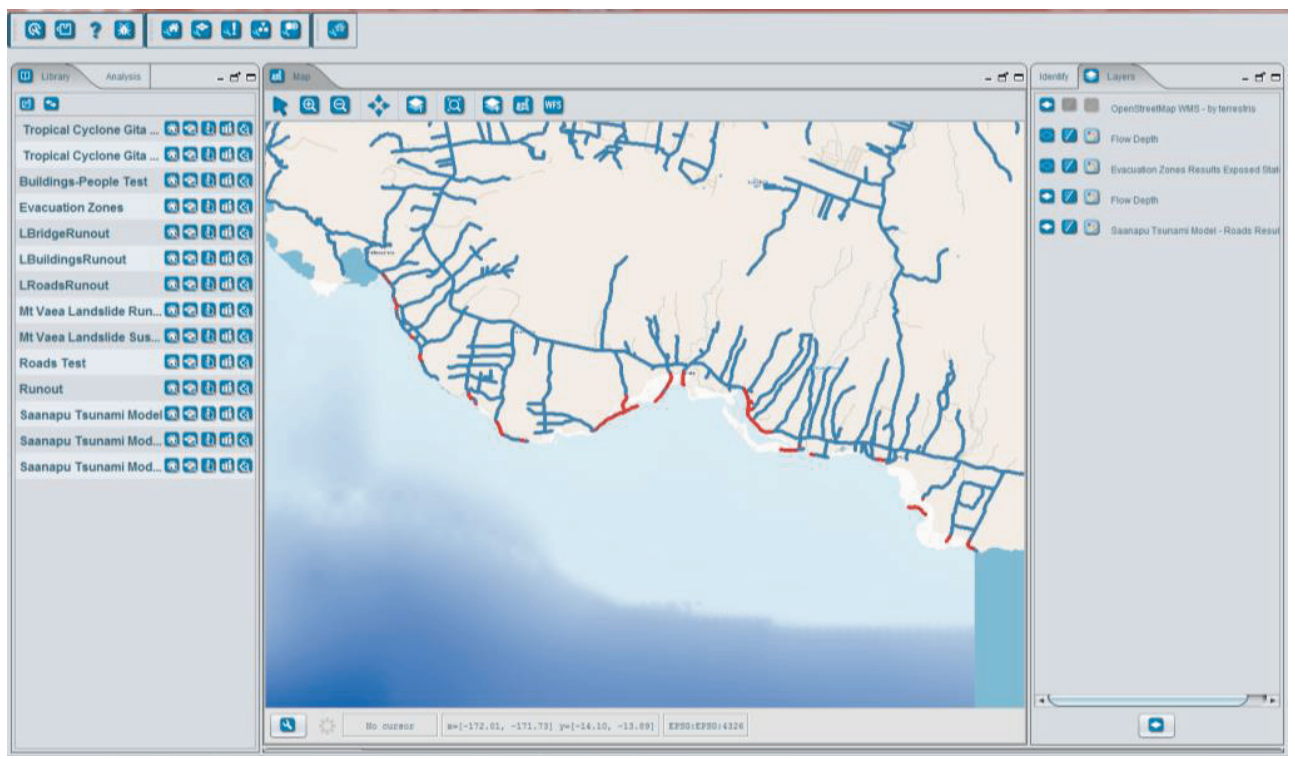

Figure 2. RiskScape software showing exposure of roads to tsunami hazard in Samoa.

Detailed information about the potential impacts to people, buildings and infrastructure sustained from the 2009 Samoa Tsunami were combined with observations published in the scientific literature to derive impact tables [5]. Impact tables describe the expected damage level that different types that asset features may experience when exposed to different tsunami flow depths. For Samoa Case Study 1, this information forms the basis for a discrete vulnerability function that estimates asset damage levels when exposed to tsunami inundation. The functions support the two impact model scenarios of the case study, enabling relative damage levels to be spatially identified and mapped to inform emergency response activities (e.g. evacuations, resources mobilization, etc.).

\subsection{Case Study 2: Near real time impact forecasting for Tropical Cyclones}

Samoa's exposure to tropical cyclones (TCs) is extreme and has the potential to impact the entire country from ridge to reef potentially causing loss of life and devastating economic damage. Building resilience to such events is fundamental given the potential for higher intensity TCs occurring in future as the climate changes, as well as the current annual risk of TCs in Samoa. This case study aims to link TC forecasts with impact modelling and may provide near-real time impact information to emergency responders as TCs are being forecast.

The three most notable TCs to cause wide-spread damage in Samoa over the last three decades include Cyclone Ofa (1990), Cyclone Val (1991), and Cyclone Evans (2012). Cyclone Val (category 4) produced wind speeds exceeding $240 \mathrm{~km} / \mathrm{h}$ and caused widespread damage to buildings, communities, vegetation and reefs. This occurred whilst recovery was still underway from the impacts of $215 \mathrm{~km} / \mathrm{h}$ wind speeds from Cyclone Ofa, and the combined impacts of the two events were devastating to Samoan communities. For the case of the Cyclone Evan (category 3), extremely intense rainfall resulted in major flooding of the 
Vaisigano and Fuluasou Rivers, subsequently impacting downstream low-lying areas of greater Apia.

Past TC events provide impact information that can be used to understand the potential impacts and loss distribution of present-day assets exposed to similar wind and flood hazards during a TC. Where applicable, wind field and rainfall intensity hazard data obtained from real-time TC forecast track/threat maps could be used to simulate wind models or rainfallflood models within days to hours in advance of the TC arrival. Impact modelling of the suggested TC wind, rainfall induced flood, and also storm surge hazard scenarios would require an assessment of the adequacy of available hazard models, asset datasets and appropriate fragility functions, including potentially refining and/or developing them where required.

In summary, this case study aims to link rapid TC forecast models for wind, rainfall and storm surge with pre-computed impact maps developed using the RiskScape tool.

\subsection{Case Study 3: Landslide risk for land use planning for Mt Vaea}

Landslides are a recognized potential hazard to housing, businesses and infrastructure in Samoa. This is particularly relevant for urban areas under pressure to expand. One such area is the Palisi neighbourhood on the slopes of Mt. Vaea in Apia. The outputs of a landslide susceptibility case study are primarily targeted at those responsible for future land use planning decisions and emergency management.

Landslides in Samoa are triggered by extreme rainfall (including but not limited to those triggered by cyclones) and earthquakes. Prior to this project, no high-resolution landslide susceptibility map suitable for planning purposes was available for Mt Vaea, and available maps coarsely defined potential landslide hazard based on slope and drainage patterns. These maps do not provide a frequency or indication of hazard characteristics such as size or extent. Therefore, it is extremely challenging to estimate landslide depth and extent from the existing information. However, some relevant data exists for this case study, such as:

- $\quad$ Rainfall data and maps are available from the Samoa Meteorology Division (SMD) of the Ministry of Natural Resources and Environment (MNRE);

- A geotechnical report is expected to be generated at the end of an ongoing feasibility and geotechnical study being conducted by OTT Construction Company for Development Consent Application (DCA);

- $\quad$ LiDAR data (1 metre resolution) is available from the Spatial Information Agency of MNRE and ground shaking maps from the Geosciences Section of SMD.

In order to develop useful products for land use planning, estimates are required of asset exposure, damage to residential buildings, roads and telecommunications infrastructure, and indirect consequences. However, given that the degree of landslide movement is difficult to estimate, a conventional vulnerability model would be challenging to replicate with any certainty. Combining information gained from consultations with local stakeholders and examination of the available literature, three key objectives were defined for improving the understanding of landslide risk on Mt Vaea: 
- $\quad$ Objective 1: Provide a simple exposure analysis for the Mt Vaea area based on landslide susceptibility maps (produced through this project) and available asset data for the area.

- $\quad$ Objective 2: Develop a risk hotspot analysis map for the case study area, using slope as well as collapse area and run-out as indications of the hazard threat, and combining with number of buildings to provide risk outputs.

- $\quad$ Objective 3: Develop a 'look up' table/s to provide the land use planners with additional information relating to the likely damage and consequences that may occur during different types of land movement.

The landslide susceptibility map developed through this project is shown in Figure 3, serving objectives 2 and 3. Vulnerability functions enabling impact model scenarios to be simulated will be developed in due course enabling asset damage/threat levels to be spatially identified and mapped to inform land use planning.

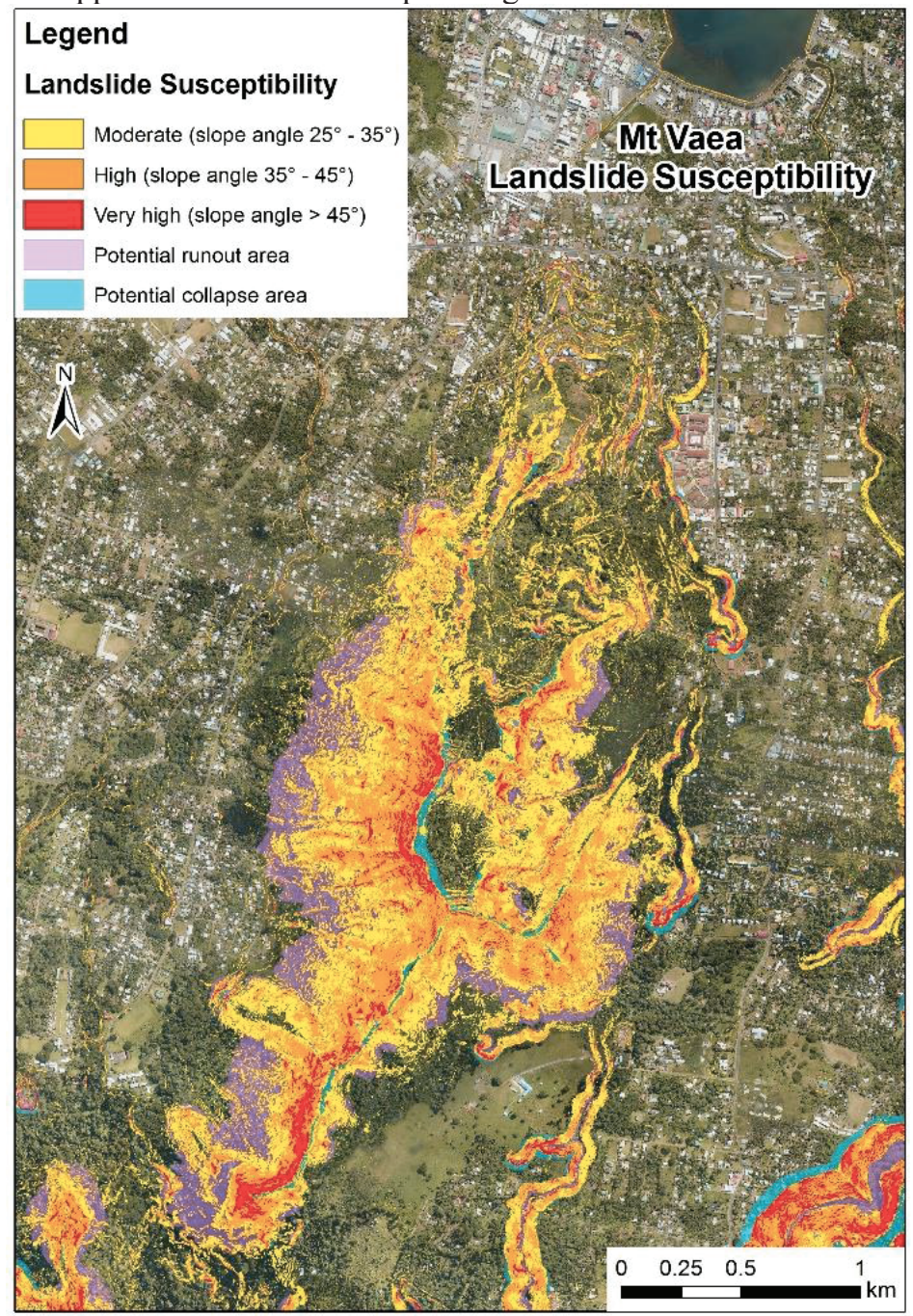

Figure 3. Landslide susceptibility map for Mt Vaea, Samoa. 


\section{Vanuatu case studies}

The three demonstration case studies for Vanuatu are:

1. Ash fall impact on Tanna Island for contingency response and preparedness;

2. Impact forecasting for agricultural production from drought and extreme rainfall;

3. Tropical cyclone impact to inform urban planning (and contingency response), a case study for Lenakel.

\subsection{Case study 1: Ashfall impact on Tanna Island}

The volcanic ashfall hazard on Tanna Island was considered by stakeholders as the most frequent damaging hazard that directly and indirectly impacts livelihoods. A literature review process revealed relatively sparse information is available in academic and practitioner publications relating to quantification of ashfall impacts on buildings or other assets across Vanuatu. As such, it was proposed that the PARTneR project collect ashfall loss and damage impact data directly from the exposed communities.

Towards this aim, focused interviews were carried out on the impacts of ashfall on villages near to Mt. Yasur volcano by the PARTneR team, including NIWA, GNS science, the Vanuatu National Disaster Management Office (NDMO), the Vanuatu Meteorological and Geohazard Department (VMGD) and other government representatives. This field study took place from 23-26 January 2018 and included 23 interviews with chiefs and authorities in 13 villages located in the three ashfall zones downwind from the volcano on Tanna Island (Figure 4).

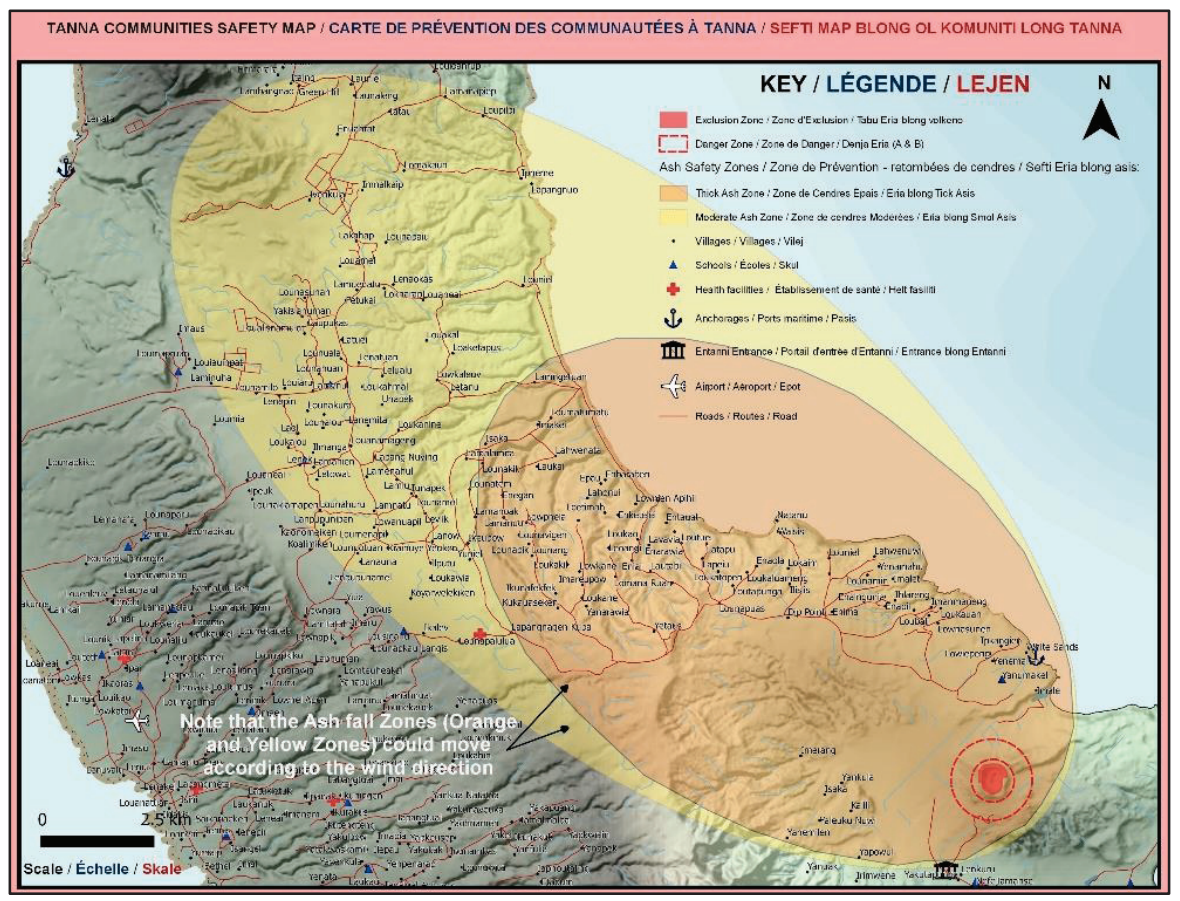

Figure 4. Ashfall zones on Tanna Island. 
The interviews gained insights into: 1) impacts of ongoing ash emissions on buildings, crops, health, livestock and infrastructure such as roads and power supplies; 2) villagers' coping capacity; and 3) whether villagers had received any information on reducing the impacts of the volcanic emissions from authorities. A range of impacts could be seen across the surveyed villages, with the most severe being seen in the locations immediately adjacent to the volcano, on the leeward side.

The information obtained is currently being analysed and the resulting draft ashfall vulnerability and impact models will be verified at a workshop in Port Vila, Vanuatu to ensure accuracy. Vulnerability functions for impacts are likely to be related to the strength of eruption, as indicated in the risk matrix shown in Table 1. The next steps in the ashfall case study will be to run the vulnerability functions through RiskScape to quantify impacts in the area. Once completed, the ashfall case study models will be handed over to the NDMO and VMGD, with the aim of using the information to inform risk reduction activities, emergency planning and management decisions in Vanuatu.

Table 1. Draft ashfall risk matrix for Mt. Yasur, Tanna.

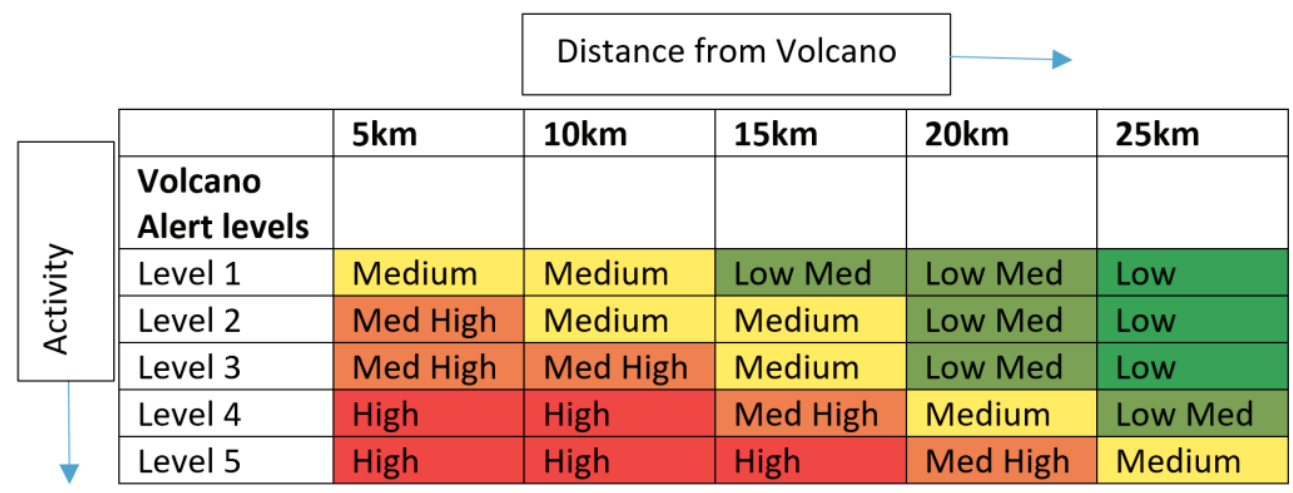

\subsection{Case study 2: Connecting drought and extreme rainfall to agricultural production}

The purpose behind the selection of this case study was to empower the government and primary production community to be better prepared for, and able to respond to, extreme levels of rainfall - either too little rainfall or too much. This work will connect with the climate early warning systems (CLEWS) that have been developed in Vanuatu.

Drought and extreme rainfall hazards adversely impact agriculture production in Vanuatu. Agricultural production on most Vanuatu islands is comprised of cash and subsistence crops that support the nutritional requirements and economy of the island populations. Thus, crop loss from drought and extreme rainfall hazards can cause significant socio-economic impacts in Vanuatu.

The study commenced with literature review on the impact of drought and extreme rainfall events on agriculture, with a particular emphasis on the likely yield loss percent for seven crops: kava, coconut, banana, cassava, taro, yam and kumara. 
This information has been used to draft potential impact tables for the crops as well as to estimate potential nutritional and economic losses. The vulnerability functions will then relate ranges of extreme rainfall or lack of rainfall and their impact on each crop.

As an example of the impact table developed, Table 2 below illustrates the agronomic characteristics and yield trends of the crop as related to drought and rainfall.

Current climate early warning drought and heavy rainfall thresholds, derived from CLEWS information, provide sectors with a climate outlook for three months in advance. These outlooks are updated on a monthly basis. Merging this information with RiskScape will help the Department of Agriculture and local farmers to plan and prepare to face average, drier or wetter than normal weather conditions and protect their crops accordingly.

Table 2. Draft impact table for Kumala (sweet potato) on crops stress to extreme rainfall and drought conditions.

\begin{tabular}{|l|l|l|l|l|}
\hline Rainfall & Index & $\begin{array}{l}\text { Crop } \\
\text { damage } \\
\text { state }\end{array}$ & Description & $\begin{array}{l}\text { Yield loss } \\
\text { Range }\end{array}$ \\
\hline $\begin{array}{l}\text { Within } 80 \% \\
\text { to } 120 \% \text { of } \\
\text { normal }\end{array}$ & Normal & 0 & No damage & $\begin{array}{l}\text { No loss beyond } \\
\text { normal }\end{array}$ \\
\hline $\begin{array}{l}40-80 \% \text { of } \\
\text { normal }\end{array}$ & $\begin{array}{l}\text { Below normal } \\
\text { rainfall }\end{array}$ & 1 & $\begin{array}{l}\text { Stunted growth and lower } \\
\text { than average yield }\end{array}$ & $\begin{array}{l}10-60 \% \text { yield } \\
\text { loss }\end{array}$ \\
\hline $\begin{array}{l}10-40 \% \text { of } \\
\text { normal }\end{array}$ & Severe drought & 2 & $\begin{array}{l}\text { Stunted growth reduction of } \\
\text { health green growth, } \\
\text { discoloured harvest, low } \\
\text { survival rate }\end{array}$ & $\begin{array}{l}60-100 \% \text { yield } \\
\text { loss }\end{array}$ \\
\hline $\begin{array}{l}\text { Less than } \\
10 \% \text { of } \\
\text { normal }\end{array}$ & $\begin{array}{l}\text { Extreme } \\
\text { drought }\end{array}$ & 3 & $\begin{array}{l}\text { Destruction of plants, very } \\
\text { low yield, high level of } \\
\text { plant loss }\end{array}$ & $100 \%$ yield loss \\
\hline $\begin{array}{l}120-160 \% \\
\text { of normal }\end{array}$ & $\begin{array}{l}\text { Above normal } \\
\text { rainfall }\end{array}$ & 4 & $\begin{array}{l}\text { Soil soaked, plant harvest } \\
\text { impacted }\end{array}$ & $\begin{array}{l}30-50 \% \text { yield } \\
\text { loss }\end{array}$ \\
\hline $\begin{array}{l}\text { Above } 160 \% \\
\text { of normal }\end{array}$ & $\begin{array}{l}\text { Severe to } \\
\text { extreme } \\
\text { rainfall }\end{array}$ & 5 & $\begin{array}{l}\text { Waterlogged soil for } \\
\text { extended period, plant roots } \\
\text { rotten, poor to no yield }\end{array}$ & $100 \%$ yield loss \\
\hline
\end{tabular}

The next steps for this case study are to share the draft vulnerability functions at a workshop for subject-matter experts in August 2018, and then finalise the data and run the functions through RiskScape. The results can then be used to improve messaging for the agricultural community to enhance preparedness and response.

\subsection{Case study 3: Tropical cyclone impacts for urban planning in Lenakel, Tanna}


The tropical cyclone case study was selected to assist Lenakel town council in their urban planning and the design of appropriate zoning areas. Lenakel is the main township of Tafea province and the third largest town in Vanuatu. The town hosts key island and provincial infrastructure such as the hospital, a secondary school, the Lenakel Presbyterian College; as well as many shops, most of the island services (banking, market house, etc.), and a wharf. In September 2015, Lenakel became the first town in Vanuatu to have a Development Control Plan. All future developments in Lenakel are now required to comply with the requirements of the municipal council.

With the Lenakel Municipal Council agreeing on the value of impact assessments for planning purposes, a literature review on tropical cyclone impacts was carried out to inform future urban planning for Lenakel town.

This case study is partnering with a German funded SPC project focused on producing multi-hazards maps for coastal areas including Lenakel town. To date, work is still underway on potential vulnerability functions for the cyclone case study, focusing on inundation hazards. Once complete, work will be delivered to:

- $\quad$ run the vulnerability function through RiskScape;

- $\quad$ create draft impact maps of inundation scenarios for various cyclone strengths;

- $\quad$ share, refine and verify the results.

The tool will be used by the town council to support legislation around zoning areas considered appropriate to mitigate cyclone hazards. An impact study focusing on Lenakel's urban planning and the design of appropriate zoning codes will be instrumental for Vanuatu's physical planners within the department of Local Authorities at the Ministry of Internal Affairs and for the Lenakel Municipal Council. The main beneficiary of this case study will be the Lenakel community, as zoning and urban planning would be designed to improve building resilience to the cyclone hazard, thus reducing loss, disruption time and potential injuries/fatalities inherent from cyclone induced damage.

\section{Conclusion}

The RiskScape framework and tool, developed in New Zealand, is applicable to diverse international contexts and is able to quantify risk for a variety of natural hazards. Whilst the outputs presented in this study are valuable for DRM practitioners and decision-makers in Samoa and Vanuatu, they ultimately demonstrate the analytical processes, types of information that can be obtained, and applications enabled (depending on the nature of a given decision) through the use of risk modelling tools.

\section{Acknowledgements}

The authors are grateful to Tatiana Goded, Heather Craig and an anonymous reviewer for their helpful comments to improve this paper.

\section{References}


1. K. Crowley, S. Williams, N. Horspool, J. Ungaro, H. Damlamian, R. Paulik, G. Turek, F. Nelson, T. Simi, S.L. Lin. Pacific Risk Tool Design Plan Summary: Samoa. NIWA client report 2016139WN. (2016)

2. K. Crowley, S. Williams, N. Horspool, J. Ungaro, H. Damlamian, R. Paulik, G. Turek, F. Nelson, T. Simi, S.L. Lin, P. Korisa, E. Garaebiti. Pacific Risk Tool Design Plan Summary: Vanuatu. NIWA client report 2016139WN. (2016)

3. A.B. King, R. Bell, D.W. Heron, I. Matcham, J. Schmidt, W.J. Cousins, S. Reese, T. Wilson, D.M. Johnston, R. Henderson, et al. RiskScape Project: 2004 - 2008. Lower Hutt (NZ): GNS Science consultancy report 2009/247. 162 p. (2009)

4. T. Simi, S. Williams. Tsunami risk and loss modelling for response planning in Samoa: Case study 1 - literature review. NIWA client report 2018015CH. (2018)

5. T. Simi, R. Paulik, S. Williams, F. Scheele, N. Horspool. Tsunami Vulnerability Model Development: PARTneR case study series Samoa. NIWA client report 2018016WN. (2018) 